\title{
The Impact of XBRL Adoption on the Information Environment: Evidence from Japan
}

\author{
ZHENYANG BAI \\ Department of Technology \\ Management for Innovation \\ Graduate School of Engineering, \\ THE UNIVERSITY OF TOKYO
}

\author{
MANABU SAKAUE \\ Faculty of Business Administration, \\ HOSEI UNIVERSITY
}

FUMIKO TAKEDA ${ }^{\dagger}$

Department of Technology Management for Innovation Graduate School of Engineering, THE UNIVERSITY OF TOKYO

\begin{abstract}
This article investigates whether and how the Japanese Financial Services Agency's mandatory use of XBRL affects investors in assessing financial information. Although regulators expect the introduction of XBRL to enhance the transparency and quality of business reporting, given the non-trivial implementation and learning costs, whether the XBRL-based disclosure reduces the information asymmetry between sophisticated and less-sophisticated investors remains an empirical question. As prior studies in other countries employing mandatory XBRL adoption provide mixed results, our analysis of the Japanese case should be somewhat insightful because Japan is one of the few countries where thousands of listed firms were forced to use the XBRL format all at once. By examining various measures in the pre- and post-XBRL periods, we provide evidence consistent with the notion that the adoption of XBRL has helped to improve the information environment, as indicated by the reduction of event returns volatility, absolute cumulative abnormal returns, changes in the standard deviation of returns, and the abnormal bid-ask spread.
\end{abstract}

\section{JEL Classificatoin: M41; M48; D82; K22; G14}

Key Words: XBRL; Information Asymmetry; Capital Market; Event Study

Data Availability: All data used in this study is publicly available.

\footnotetext{
* We would like to thank the anonymous reviewers and participants at the 2013 Annual Congress of the European Accounting Association, the 2013 Annual Conference of the Asian Academic Accounting Association, and the 4th The Japanese Accounting Review Conference for their useful comments and suggestions. All remaining errors are our own.

$\dagger$ Corresponding author. Address 7-3-1 Hongo, Bunkyo-ku, Tokyo 113-8656 Japan. Telephonelfax +81-3-5841-1191

E-mail takeda@tmi.t.u-tokyo.ac.jp

Received August 7, 2013; accepted June 24, 2014; available Online September 11, 2014 (Advance publication by J-STAGE)

DOI: 10.11640/tjar.4.2014.03
} 


\section{Introduction}

The eXtensible Business Reporting Language (XBRL) is undergoing a rapid transition from the vision phase to becoming a practical global standard for financial and business reporting. XBRL is intended to allow the efficient compilation, distribution, and usage of financial statements. It is an open standard that provides a way to model business information and to articulate its semantic meaning. ${ }^{1}$ Internationally, the XBRL data standard is a platform for addressing the problem of data integrity, timeliness and reusability. In Asia, stock exchanges in China, Japan, Singapore and South Korea have all mandated the use of XBRL data. ${ }^{2}$ In April 2009, the U.S. Securities and Exchange Commission (SEC) mandated that listed firms report their financial statement data using XBRL with the goal of using XBRL as a binding and exclusive format in the U.S. in the future. As of 2011, there were 50 XBRL projects in 15 European countries that were established or in progress. ${ }^{3}$

A considerable amount of research related to XBRL has been carried out over the last decade, with a significant increase in related publications in recent years. Among them, research on the effects of the adoption and diffusion of XBRL on capital markets is one of the more emphasized areas. Several studies provide evidence that the introduction of XBRL reduces information asymmetry in both voluntary and mandatory XBRL reporting (Tan and Shon 2009; Efendi et al. 2010; Yoon et al. 2011; Kim et al. 2012), while more recent research provides contradicting results in terms of mandatory adoption (Blankespoor et al. 2014).

Because prior studies provide mixed results, the question of whether the use of XBRL helps to improve the information environment in capital markets remains an empirical question. The present study aims to contribute to related literature by examining Japanese data. We believe that investigation of the Japanese case should provide useful empirical results in two ways. First, Japan employed mandatory XBRL adoption, which is more controversial than voluntary adoption, as prior studies provide mixed results on the effect of mandatory adoption. It should be more important to investigate the effect of mandatory XBRL adoption compared to the effect of voluntary adoption.

Second, Japan is one of the few countries where approximately 5,000 listed firms and 3,000 funds were forced to use the XBRL format at the same time (Kobayashi 2008). ${ }^{4}$ Compared to

${ }^{1}$ According to the U.S. SEC, the use of XBRL will allow investors and analysts to "capture and analyze information more quickly and at less cost than is possible using the same financial information provided in a static format" (SEC 2009).

${ }^{2}$ China was the first capital market to adopt XBRL. In 2004, the China Securities Regulatory Commission, the Shanghai Stock Exchange and the Shenzhen Stock Exchange mandated all publicly traded firms to file their financial statement using XBRL as part of their effort to increase the overall attractiveness of the Chinese equity markets (Peng et al. 2011).

${ }^{3}$ Among the projects in Europe that involved mandatory filings are those by the U.K. Companies House, Belgium's National Bank, banking industry and government in Spain, Danish Commerce and Companies Agency, and Italy Infocamere (ISARG 2011).

${ }^{4}$ While the U.S. SEC employed a phase-in period to adopt XBRL, Japan's EDINET introduced the official XBRL mandate in 2008 after two pilot projects in which about 50 of the filing companies chosen by the FSA tested the taxonomies in the first project and 1,223 firms voluntarily participated in the second project. The XBRL-formatted financial data under the pilot projects were disclosed temporarily from August 13 to 31, 2007, although it is questionable how many investors noticed this disclosure.

It is true that while the phased adoption (such as in the U.S.) enables researchers to have a control sample that does not employ XBRL, we cannot have such a control sample because all listed firms in Japan were forced to employ 
Japan, research on other countries covers a relatively small number of observations. For instance, the U.S. SEC required large accelerated filers (approximately 500 firms) ${ }^{5}$ to disclose their financial information in the XBRL format in 2009, although more than 10,000 listed firms were required to do so after December 2011. The prior study of the Korean implementation of XBRL investigates 550 listed firms (Yoon et al. 2011), while the study of the Chinese case covers approximately 1,300 listed firms per year (Peng et al. 2011).

Japan has been an early and active adopter of XBRL. ${ }^{6}$ The XBRL Japan organization was established as far back as April 2001 to help promote and create awareness of XBRL within the country. Since the latter half of the 2000s, XBRL has been adopted and used in production by key governmental and public organizations (Hoffman and Watson 2010), including the Financial Systems and Bank Examination Department of the Bank of Japan (BOJ), the National Tax Agency of Japan (NTA), the Tokyo Stock Exchange (TSE), and the Financial Services Agency (FSA).

The FSA has an Electronic Disclosure for Investors' Network (EDINET) system, and all listed firms and investment funds in Japan are required to file their disclosure documents using the system. The FSA launched a new EDINET system in preparation for the adoption of XBRL in 2008. All filers are mandated to submit the financial statements for fiscal years starting in or after April 2008 in the XBRL format. The XBRL mandate is part of the FSA's continuing efforts to use XBRL to achieve multinational interoperability together with the International Accounting Standards Committee Foundation and the U.S. SEC.

The adoption of XBRL in the new EDINET system is expected to enable investors to download financial data and directly process and analyze the data. If the use of XBRL is successful in reducing information processing costs and information asymmetry, the introduction of XBRL may not only assist in enhancing the transparency of the securities market but also improve the information structure in ways that will enhance the efficiency of economic activities in general.

The purpose of this paper is to examine whether and how the FSA's mandatory financial reporting using XBRL has affected investors in assessing financial information. Specifically, we investigate the effects of using XBRL on the information environment in the Japanese market by assessing various measures in the pre- and post-XBRL periods. Our results are consistent with the notion that the adoption of XBRL helps to improve the information environment in the Japanese market, as shown by the reduction of event returns volatility, absolute cumulative abnormal return, change in the standard deviation of return, and abnormal bid-ask spread. ${ }^{7}$

XBRL all at once. However, the phrased adoption may cause difficulty in isolating the effects of the XBRL adoption from the effects of other economic events occurring at different times, while the one-time adoption requires us to consider only the effects of the events occurring at the same time.

${ }^{5}$ Specifically, the large accelerated filers here means those using U.S. GAAP with a worldwide public float over $\$ 5$ billion.

${ }^{6}$ A detailed description on the XBRL adoption in Japan is provided in Appendix 1.

${ }^{7}$ One may argue that the timing of XBRL adoption was so close to the world financial crisis in 2008 that it may make it difficult to isolate the effects of XBRL from the effects of the world financial crisis. However, we can reasonably assume that the financial crisis may increase uncertainty and information asymmetry, while XBRL adoption is expected to reduce information asymmetry, which is consistent with our results. We also try to eliminate the effect of the financial crisis in our sensitivity analysis. Another event that may have affected stock prices in the sample period is a change in financial reporting systems, including the beginning of quarterly reporting. However, prior studies report that this did not affect stock markets (Kagaya et al. 2011). 
The rest of this article is organized as follows. Section 2 provides a literature review and hypothesis development. Section 3 describes the data and methodology used in the research. Sections 4 and 5 discuss the empirical results and robustness tests, respectively. Lastly, Section 6 provides the conclusions for the paper.

\section{Literature Review and Hypothesis Development}

\subsection{Literature review}

A considerable amount of research related to XBRL has already been carried out over the last decade, with a significant increase in relevant publications in recent years. ${ }^{8}$ According to Mike Starr from the U.S. SEC, the main benefits of using XBRL are more timely access and greater transparency for investors and enhanced efficiency in analyzing the data by regulators, both of which will result in a more effective regulatory process (Starr 2012). Both the market and companies stand to benefit from this gained transparency, as investors appreciate having more information about the company readily available. ${ }^{9}$ This improved, transparent, and real-time financial reporting and disclosure of data in the XBRL format are expected to reduce each participating firm's cost of capital (Pinsker and Li 2008). ${ }^{10}$

One drawback is that the large setup and learning costs of implementing XBRL reporting may deter both filers and investors from using XBRL. Because of its complicated technology, the introduction of XBRL may involve many difficulties, resulting in an increase in preparation costs. In fact, the U.S. committee on corporate reporting of Financial Executives International also expressed its concerns that requiring filers to adopt XBRL would result in increased costs with no improvements to internal processes (Dzinkowski 2008). In addition, prior studies cast doubt on the reporting quality of XBRL, as errors or the incompleteness of financial reporting are still observed (Zhu and Fu 2009; Debreceny et al. 2010; Bartley et al. 2011; Roohani and Zheng 2011). ${ }^{11}$

${ }^{8}$ The increased efforts related to the use of XBRL by the U.S. SEC together with the availability of the first empirical data from real XBRL-based financial reports from 2008 may have been a significant driving force to explain the increase in XBRL publications in recent years (Roohani et al. 2010).

${ }^{9}$ The increased transparency through the use of the XBRL may also improve the corporate governance of filers. For instance, Peng et al. (2011) examine the level of total accruals that firms report before and after XBRL adoption in China. Their results indicate a lower level of total accruals in the post-XBRL period, with this effect most prominent for high-growth firms, small firms, and firms in high-technology industries. They argue that XBRL implementation decreases an investor's information acquisition costs and improves an investor's ability to detect earnings management. Accordingly, managers are pressured to reduce accruals. In addition, Premuroso and Bhattacharya (2008) examine whether early and voluntary filers of financial information in XBRL format demonstrate superior corporate governance and operating performance relative to their non-adopting peers. The results of their study suggest that early and voluntary XBRL adoptions are indeed indicators of superior corporate transparency and related corporate governance that are expected to benefit adopting firms in the long run.

${ }^{10}$ Another advantage of using XBRL tags is that otherwise unused information in the notes becomes more usable. Henselmann and Scherr (2012) develop an automated content analysis technique to assess the bankruptcy of companies using XBRL tags. A list of potential red flags based on the U.S. Generally Accepted Accounting Principles (GAAP) taxonomy is developed based on the annual reports of 26 companies with Chapter 11 bankruptcy filings and a control group. The empirical results reveal that the red flag item list has predictive power of bankruptcy risk. Logistic regression results also showed that the predictive power increases as the bankruptcy filing date approaches.

${ }^{11}$ The literature review on the reporting quality of XBRL is presented in Appendix 2. 
These shortcomings raise the issue of whether the information environment (asymmetry) is improved (reduced) by the introduction of XBRL. One of the important factors that will allow us to answer this question is whether the accessibility of financial information is improved by the introduction of XBRL. From the viewpoint of investors, a unique aspect of the XBRL mandate is that it requires investors to incur significant learning costs to achieve the intended benefits. Thus, those that perceive the costs to outweigh the benefits may decide to forego or delay the use of XBRL. For example, investors with relatively fewer resources may refrain from the use of XBRL until they have a better understanding of the associated costs and it is likely that only a subset of investors will choose to use XBRL in the initial year of mandate.

Two prior studies examine whether the use of XBRL can help investors to acquire financial information based on experimental methodology (Hodge et al. 2004; Pinsker and Wheeler 2009). Hodge et al. (2004) employ experimental research and examine whether using an XBRLenhanced search engine helps nonprofessional financial statement users acquire and integrate related financial information when making an investment decision. Their results suggest that XBRL should be beneficial for the users by improving the transparency of firms' financial statement information, although nonprofessional users may not automatically use XBRL, as half of their experimental participants with access to XBRL technology do not use the technology.

Pinsker and Wheeler (2009) complement the findings of Hodge et al. (2004) by investigating the relationship between XBRL use and perception by surveying 61 MBA students as proxies for nonprofessional investors. Their results indicate that nonprofessional investors who use XBRL-formatted information have more accurate perceptions of analytical effectiveness and efficiency in utilizing XBRL-based information compared to paper-based investors performing non-directed analysis.

Although the experimental studies suggest the improved accessibility of financial information following the introduction of XBRL, other prior studies examine whether the introduction of XBRL is associated with the reduction of information asymmetry. Among them, earlier studies investigate the effect of voluntary filing in the XBRL format on the information environment (Tan and Shon 2009; Efendi et al. 2010).

Tan and Shon (2009) report that U.S. firms that voluntarily file in the XBRL format enjoy reduced information asymmetries in the form of reduced bid-ask spreads. They also find that smaller firms, whose information environment may be poor, are more likely to attract more analysts after they decide to file in the XBRL format. Efendi et al. (2010) show significant price movement on the date of voluntary XBRL filings in the U.S. They argue that XBRL conveys incremental value-relevant information about the market due to the ease of comparability and predictability, enhancing the relevance of financial reports. They also document that smaller investors benefit more due to reduced costs associated with information processing and analysis from the adoption of XBRL.

While Tan and Shon (2009) and Efendi et al. (2010) report the reduction of information asymmetry in voluntary disclosure, other studies examining the effect of mandatory XBRL adoption provide mixed results (Yoon et al. 2011; Kim et al. 2012; Blankespoor et al. 2014). Kim et al. (2012) investigate the impact of mandatory XBRL reporting and find an increase in information efficiency, a decrease in event return volatility, and a reduction in the change in stock returns volatility for 425 U.S. mandated filers in the post-XBRL adoption period. Yoon et al. (2011) address the question of whether the mandatory use of XBRL may reduce the information asymmetry in the Korean Stock Market. Their results demonstrate the presence of a significant 
and negative association between XBRL adoption and information asymmetry, which implies that the adoption of XBRL may lead to the reduction of information asymmetry. In addition, the effect of XBRL adoption on reducing information asymmetry is more prominent for large firms than for small- and medium-sized firms in Korea.

More recently, however, Blankespoor et al. (2014) examine the initial impact of the use of XBRL on information asymmetry after the U.S. SEC mandate. They provide evidence of a higher abnormal bid-ask spread, a reduction in abnormal liquidity, and a decrease in abnormal trading volume for XBRL-adopting firms around 10-K filings. As a conclusion, they claim that the SEC's objective of improving the information playing field might not have been met during the initial year of XBRL adoption.

\subsection{Hypothesis development}

As discussed above, XBRL is an internationally standardized computer language aimed at allowing the efficient compilation, distribution, and usage of financial statements. However, whether the use of XBRL reduces information asymmetry among investors is not so plausible. In fact, there are several issues that need to be checked before answering this question. ${ }^{12}$ According to the SEC (2009, 125-131), the benefits of using XBRL-based disclosure can be summarized as follows: XBRL (1) allows investors to acquire financial statement data more timely and with lower costs and to analyze larger amounts of data, ${ }^{13}(2)$ provides richer sets of data than those provided by existing data aggregators, and (3) enables investors to compare data across firms more efficiently through a structured taxonomy. However, to enjoy the benefits of the XBRLbased disclosure, filers and investors are expected to incur setup and learning costs, respectively. ${ }^{14}$ The SEC (2009, 132-146) specifies the former as costs of submitting and posting interactive data. Investors may pay either for the costs of learning the large taxonomy and tagging structure, or for the use of XBRL-enabled software and services that read XBRL-tagged data. Accordingly, investors are likely to compare costs to benefits and decide whether to use the new technology.

These costs and benefits may differ between large and small investors, generating two possible impacts of XBRL adoption on information asymmetry. One possibility is that large investors may already have similar technology and decide not to use the new technology. If this is the case, whether small investors receive benefits from XBRL adoption is the key to observing the reduction of information asymmetry. Unfortunately, there is no report to show how many investors directly use XBRL-formatted data in Japan. However, as discussed in the previous subsection, two prior experimental studies suggest the improved accessibility of financial information following the introduction of XBRL (Hodge et al. 2004; Pinsker and Wheeler 2009). In addition, several new services have started to provide small investors with financial information based on the XBRL-formatted data less expensively. These services include: kabupro.jp (http://ke.kabupro.jp/),

\footnotetext{
${ }^{12}$ Blanskespoor et al. (2014) discuss similar issues.

${ }^{13}$ Prior to the electronic disclosure system, the financial statements (yuka shoken houkokusho) cost approximately 1,500-2,000 yen per firm, resulting in 5 million yen and spaces for files for 3,000 firms. In addition, users had to copy and paste financial data, which made individual investors difficult to handle the data easily.

${ }^{14}$ We agree that investors do not always need to know about XBRL because they can analyze the data read and provided by XBRL-enabled software and services. However, investors can reduce the costs of payments for the use of XBRL-enabled software and services if they have sufficient knowledge about XBRL to use XBRL-formatted data. In other words, investors, who do not want to pay for the use of XBRL-enabled software and services, will have to pay learning costs to know about XBRL.
} 
Ufo On-demand (http://www.ufo-on-demand.com/), Ufo Catcher (http://www.ufocatch.com/), minna no zaimu data (http://www.in $4 \mathrm{mx} . \mathrm{com} /$ ), and so on. These new services could enable small investors with fewer resources to access a richer set of financial data, benefitting indirectly from the new technology. If this is the case, the XBRL adoption may decrease information asymmetry between large and small investors.

Another possibility is that large investors may enjoy greater benefits from XBRL adoption than do small investors, widening the information asymmetry between them. For instance, the XBRL enables large database companies to collect financial data automatically and to provide their services immediately and more accurately than before when they typed financial data into the computer system. ${ }^{15}$ If this is the case, the XBRL adoption may increase the information asymmetry because only large investors with rich resources are likely to benefit from such improved services provided by large database companies.

Considering these issues, whether the XBRL adoption reduces information asymmetry among investors remains an empirical question. To conduct our empirical analysis, we set the following null hypothesis:

$H_{0}$ : The XBRL disclosure does not affect the information environment (asymmetry) around annual securities filing dates.

As discussed in the previous subsection, prior studies report the reduction of information asymmetry among investors in the case of voluntary XBRL adoption but provide mixed results in the case of mandatory XBRL adoption. This mixed result suggests the possibility that mandatory XBRL adoption requires larger setup and learning costs to filers and users than voluntary adoption. ${ }^{16}$ Our use of the Japanese setting can contribute to the literature because the Japanese case provides evidence based on a large number of Japanese listed firms that were mandated to disclose financial statements by using the XBRL format all at once. In the following sections, we investigate the effects of the mandatory XBRL requirement on the information environment around the annual securities filing by using data on firms listed in the first section of the TSE. ${ }^{17}$

\section{Research Design and Data}

\subsection{Information environment measures}

To examine the impact of the XBRL mandate on the information environment in the Japanese market, we employ several measures that were used in prior studies. Specifically, we focus on five measures, including event returns volatility (ERV), absolute cumulative abnormal returns (ACAR), the change in standard deviation of daily stock returns ( $\triangle$ STDDEVRET), abnormal bid-ask spread (ASPREAD), and abnormal trading volume (AVOL). A summary of variable definitions is presented in Appendix 3.

\footnotetext{
${ }^{15}$ This case is reported in the workshop involving a Japanese branch of the world large financial database company.

${ }^{16}$ In general, mandatory XBRL adoption is expected to require larger setup and learning costs to filers and users than voluntary adoption because of the limited resources (time, money, human resources, etc.) available both inside and outside of them.

${ }^{17}$ The TSE has two sections. Larger and more established firms are supposed to be listed in the first section. We focus on the first section of the TSE because this is the most liquid market in Japan, where the most stocks are traded every day, while the other markets are less liquid and thus a nontrivial number of stocks are not traded every day, causing difficulty in obtaining stock price data throughout the sample period.
} 


\section{FIGURE 1: TIMELINE OF THE EVENT STUDY}

(a) Pre-XBRL period (January 1, 2008 - June 30, 2008)

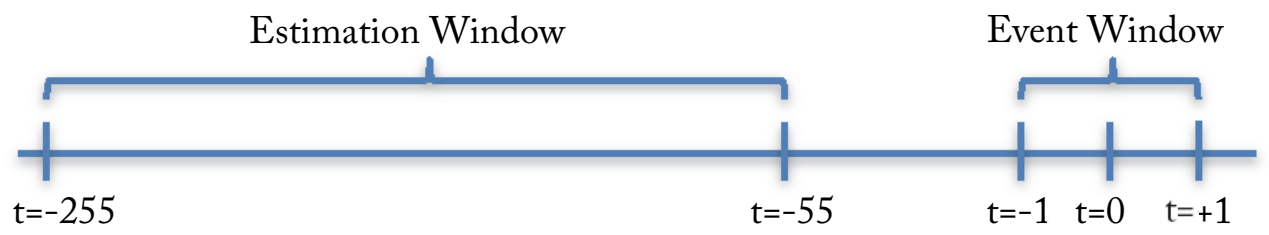

(b) Post-XBRL period (January 1, 2009 - June 30, 2009)

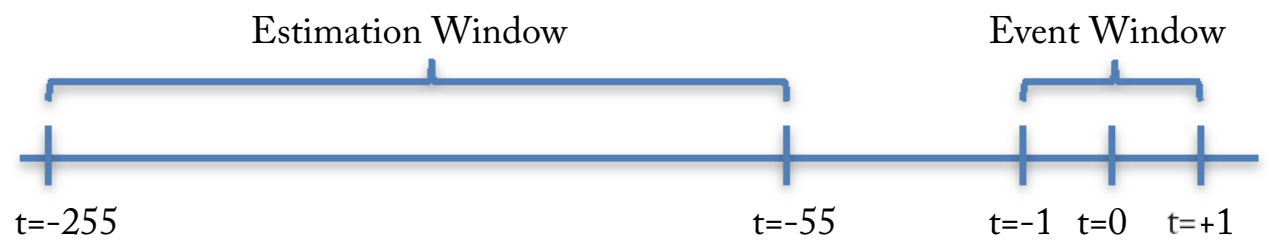

Note: $\mathrm{t}=0$ is the event date when the firm's annual securities report is filed in EDINET.

The first two measures are calculated by using abnormal returns (ARs) based on the event study. To estimate ARs, we employ the standard event study methodology based on MacKinlay (1997). The event here is defined as the day when the firm submits its annual securities reports. AR is defined as the actual ex-post return of the security over the event window, the period in which the market is considered to be affected by the event, minus the expected return of the security over the event window, as follows:

$$
A R_{i t}=R_{i t}-E\left(R_{i t} \mid X_{t}\right)
$$

where $A R_{i t}, R_{i t}$, and $E\left(R_{i t} \mid X_{t}\right)$ are the abnormal, actual, and expected (normal) returns, respectively, for firm $i$ at period $t . X_{t}$ is the conditioning information for the expected return.

To calculate the expected return, we estimate the standard market model over the estimation window, the period in which the market is not affected by the event. The market model assumes a stable linear relation between the return of any given security and the return of the market portfolio. Denoting $R_{m t}$ as the market return, the market model is expressed as follows:

$$
\begin{aligned}
& R_{i t}=\alpha_{i}+\beta_{i} R_{m t}+\varepsilon_{i t} \\
& E\left(\varepsilon_{i t}=0\right) \quad \operatorname{var}\left(\varepsilon_{i t}\right)=\sigma_{\varepsilon}^{2}
\end{aligned}
$$

where $\varepsilon_{i t}$ is the zero-mean disturbance term. Here, $\alpha_{i}$ and $\beta_{i}$ are the parameters of the market model. We use the Tokyo Stock Price Index (TOPIX) as our market portfolio because TOPIX tracks all firms listed on the first section of the TSE. Our estimation window is set at one year before the annual securities report filing dates, namely, 200 trading days from day $\mathrm{t}=-255$ to day $\mathrm{t}=-55$ (Figure 1). Our event window is set around the annual securities filing date from day $\mathrm{t}=-1$ to day $\mathrm{t}=+1$. 
We then calculate the five measures that capture the information environment. The first measure is ERV. Following prior studies (Baily et al. 2003; Heflin et al. 2003; Francis et al. 2006; Kim et al. 2012), ${ }^{18} \mathrm{ERV}$ is defined as an arithmetic sum of the absolute values of ARs over the event window, as follows:

$$
E R V=\sum_{t=-1}^{1}\left|A R_{t}\right|
$$

Because AR indicates the gap between the full information, post-event stock return and the expected return based on parameters estimated by using pre-event returns, ERV is also regarded as the information gap, which measures the value of information that is not reflected in the stock price prior to the filing date. A smaller ERV implies a market environment with lower information asymmetry.

The second measure is ACAR, which is calculated by the Cartesian product of ARs in the event window, following Heflin et al. (2003) and Kim et al. (2012), as follows:

$$
A C A R=\left|\prod_{t=-1}^{1}\left[1+A R_{t}\right]-1\right| .
$$

Similar to ERV, ACAR captures the gap between the full information, post-event stock price and a pre-event price by taking the absolute deviation between the actual return and the expected return. A higher ACAR indicates a larger information gap and higher information asymmetry between informed and uninformed investors. Conversely, a smaller ACAR demonstrates a smaller deviation, which implies an improved information environment.

The third measure is $\triangle$ STDDEVRET. Following Kim et al. (2012), $\triangle$ STDDEVRET is defined as the change in the standard deviation of daily stock returns before and after the firm's annual securities report filing dates. The construction of this variable is carried out by first calculating the standard deviation of returns using daily return data for 30 days before the annual securities report filing dates followed by calculating the standard deviation of returns for 30 days after the annual securities report filing dates, as follows:

$$
\triangle S T D D E V R E T=\sqrt{\frac{1}{30} \sum_{t=0}^{30}\left(R_{t}-\bar{R}_{t}\right)^{2}}-\sqrt{\frac{1}{30} \sum_{t=-30}^{0}\left(R_{t}-\bar{R}_{t}\right)^{2}} .
$$

$\triangle$ STDDEVRET indicates the frequency of information reaching the market and the extent of information asymmetry among investors. As a result, we expect that a reduction in the change in the standard deviation if the adoption of XBRL decreases the information asymmetry.

The fourth measure is ASPREAD, which is defined as the difference between the average daily bid-ask spread between the event window (post-event period) and the estimation window (pre-event period). Following prior studies (Yoon et al. 2011; Blankespoor et al. 2014), ASPREAD is expressed as follows: ${ }^{19}$

${ }^{18}$ Baily et al. (2003), Heflin et al. (2003), and Francis et al. (2006) investigate the impact of the Regulation Fair Disclosure (Reg FD) on the information environment. Reg FD prohibits firms from privately disclosing valuerelevant information to professional investors without disclosing the same information to the public at the same time.

${ }^{19}$ To calculate the bid-ask spread, we follow Corwin and Schultz (2012) and use a bid-ask estimator developed from daily high and low prices. 
$A S P R E A D=$ Average daily spread ${ }_{\text {Event window }}-$ Average daily spread Estimation window .

The bid price is quoted by buyers and the ask price is quoted by sellers for a given security. Information asymmetry increases together with the bid-ask spread. Thus, if the XBRL mandate decreases information asymmetry, we predict a smaller bid-ask spread in the event window than that in the estimation window. In other words, the adoption of XBRL is likely to decrease ASPREAD.

The last measure is AVOL. Following prior studies (Baily et al. 2003; Francis et al. 2006; Miller 2010; Blankespoor et al. 2014), AVOL is defined as the difference between the mean daily trading volume during the event window and the mean daily trading volume during the estimation window divided by the standard deviation (STDDEV) of daily trading volume during the estimation window, as follows:

$$
A V O L=\frac{\text { Average daily volume } \text { Event window }- \text { Average daily volume }_{\text {Estimation window }}}{\text { STDDEV daily volume }}
$$

Investors are not able to fully process all available information due to limited time and resources. As such, information to be processed is selectively chosen. If the XBRL filings are relatively less difficult to process, investors will find more incentives to process them, as the costs required may be less than the benefits of obtaining the information. In other words, investors should be more willing to trade in such an environment. Thus, if the adoption of XBRL decreases information processing costs, we expect a larger average daily volume in the event window than that in the estimation window. In other words, we expect the increase of AVOL in the post-XBRL period.

\subsection{Multivariable regression models}

Using variables described above, we estimate the following regression models to assess the effects of XBRL adoption on the information environment in Japan:

$$
\begin{aligned}
& E R V=\alpha_{0}+\alpha_{1} X B R L+\alpha_{i} \sum_{k=i}^{n} \text { CONTROLS }+\epsilon \\
& A C A R=\alpha_{0}+\alpha_{1} X B R L+\alpha_{i} \sum_{k=i}^{n} \text { CONTROLS }+\epsilon \\
& \triangle S T D D E V R E T=\alpha_{0}+\alpha_{1} X B R L+\alpha_{i} \sum_{k=i}^{n} \text { CONTROLS }+\epsilon \\
& \text { ASPREAD }=\alpha_{0}+\alpha_{1} X B R L+\alpha_{i} \sum_{k=i}^{n} \text { CONTROLS }+\epsilon \\
& A V O L=\alpha_{0}+\alpha_{1} X B R L+\alpha_{i} \sum_{k=i}^{n} \text { CONTROLS }+\epsilon
\end{aligned}
$$

where XBRL is a dummy variable, which takes one if the annual securities filing date is in the post-XBRL period and zero otherwise. CONTROLS presents control variables that are likely to be associated with the information environment. XBRL is our primary variable of interest. If the adoption of XBRL improves the information environment, we expect XBRL to be negatively correlated with ERV, ACAR, $\triangle$ STDDEVRET, and ASPREAD and positively correlated with AVOL, as explained in the previous sub-section.

CONTROLS are included to ensure that our results are not driven by other firm-specific characteristics that may affect the information environment. Specifically, CONTROLS include 
firm size (SIZE), the market-to-book ratio (MB), the earnings-to-price ratio (EPRATIO), leverage (LEV), a loss indicator (LOSS), the IT \& Services sector (TECH), the percentage of shares held by foreign shareholders (GOV), the return volatility for the estimation window (RETVAR), an indicator of the negative sign of the cumulative AR (NEGCAR), and the cumulative absolute AR for the corresponding quarter (CAAR).

Prior research has shown that there is a positive correlation between a firm's extent of disclosure and its size (Ajinkya et al. 2005). We include SIZE, which is the natural log of market capitalization at the end of the corresponding fiscal year. Considering larger firms' ability to sustain a comparative advantage through superior financial and human resources available, we expect negative correlation between SIZE and information asymmetry.

$\mathrm{MB}$ is defined as the ratio of the firm's market capitalization to the total equity at the end of the fiscal year. MB is included to capture the perceived potential growth in the market. We also include EPRATIO of the firm at the end of the fiscal year as a proxy for expected growth in earnings, as prior research argues that growth expectations increase stock price responses to earnings (Skinner and Sloan 2002). Because high-growth firms are likely to have higher information asymmetry, we expect a positive correlation between MB/EPRATIO and information asymmetry.

Firms operating at higher leverage generally have higher financial risks, and they tend to be inclined to disclose more financial information to provide assurance to creditors and confidence to the public (Kothari et al. 2009). As a result, we include LEV, which is defined as the ratio of long-term debt divided by total assets at the end of the fiscal year. In addition, prior research has shown that financial reporting errors are negatively correlated with performance and that the presence of a net income loss impedes the market's ability to accurately forecast the firm's earnings (Heflin et al. 2003). To control this negative effect, we employ a dummy variable LOSS, which is equal to one if the net income in the corresponding fiscal year is negative and zero otherwise. Based on the explanations above, we expect a negative (positive) correlation between LEV (LOSS) and information asymmetry.

We also include an industry dummy variable TECH for technology firms, which is equal to one for firms that are classified under IT \& Services and zero otherwise. Technology firms usually exhibit financial statements that are more difficult to interpret due to financial reporting models that may not properly capture value-relevant information related to intellectual property and $\mathrm{R} \& \mathrm{D}$ activities. We expect a positive correlation between TECH and information asymmetry. GOV is a percentage of shares held by foreign shareholders as a proxy for corporate governance. Because foreign shareholders are expected to be more demanding for disclosure in Japan than domestic shareholders, firms with a high foreign shareholder ratio are expected to face less information asymmetry.

The last three variables are related to price variability, which may increase information asymmetry. RETVAR controls for firm-specific inherent price variability, which is defined as the standard deviation of the firm's ARs during the market model estimation window for the corresponding annual securities filing date. We expect RETVAR to be positively related to information asymmetry (Beaver 1968). NEGCAR is a dummy variable, which takes 1 if cumulative ARs during the estimation window are negative and 0 otherwise. NEGCAR controls for another dimension of price variability. Prior studies suggest that downward price movements are greater than upward price movements (Heflin et al. 2003). Lastly, CAAR, which is a cumulative absolute AR around the filing date from $t=-30$ to $t=+30$, is included. CAAR measures 
TABLE 1: SAMPLE SELECTION

\begin{tabular}{lrr}
\hline \hline & No. of firms & \multicolumn{1}{c}{ Weight } \\
\cline { 2 - 3 } Firms listed in the first section of the TSE as of May 31, 2012 & 1,685 & $100.0 \%$ \\
(less) Firms with incomplete data and those do not exist between January 1, 2007, and June 30, 2009 & 547 & $32.5 \%$ \\
\hline Sample firms & 1,138 & $67.5 \%$ \\
\hline
\end{tabular}

the total information flow, and firms with a larger information flow are expected to have larger information gaps at any given time. We expect this variable to be positively correlated with information asymmetry (Heflin et al. 2003).

\subsection{Sample selection}

We downloaded all of the firms listed in the first section of the TSE from the TSE's homepage to obtain 1,685 domestic firms as of May 31, 2012 (Table 1). The FSA has its own EDINET code to uniquely label firms found in its EDINET database. The corresponding EDINET code is first located from the FSA's homepage. Then, a list of filing dates for the annual securities reports is downloaded from the Ullet website (http://www.ullet.com $)^{20}$ for all the firms between January 1, 2007, and June 30, 2009. (This is similar to the Form 10-K required by the U.S. SEC.) Data related to financial statements, such as net income, total long-term debt, total assets, and total debt are also downloaded from the Ullet website. Data with respect to stocks, which include the high price, low price, closing price, opening price and volume, are downloaded from Yahoo! Finance Japan. Lastly, the number of shares outstanding for each firm is obtained from Nikkei NEEDS-Financial Quest.

After accounting for incomplete data and matching requirements, we have 2,276 annual securities filing dates from 1,138 firms. These securities filing dates are matched for each of the 1,138 firms to allow a more accurate comparison between the pre-XBRL and post-XBRL period (1,138 annual securities filing dates for the pre-XBRL period and the post-XBRL period). We set the period between January 1, 2008, and June 30, 2008 as the pre-XBRL period and the period between January 1, 2009, and June 30, 2009 as the post-XBRL period. Because most Japanese firms have their fiscal year ending on March 31, the majority of annual securities filing dates of the sample are found in June.

Table 2 shows the number of the firms in our sample broken down by TOPIX Sector Code. The sample has a large representation from Construction \& Materials, Raw Materials \& Chemicals, Electrical Appliances \& Precision Instruments, and IT \& Services, and Others. However, these industries each account for only approximately 10 percent of the total sample. Overall, the sample is well distributed across several broad industry groups. This broad representation should alleviate concerns that the results are driven by any specific industry.

${ }^{20}$ Ullet is a web service by Businesswire (a Berkshire Hathaway company), which organizes financial data of approximately 4,000 companies listed on the stock markets in Japan. The information provided by Ullet is compiled from the Japanese FSA EDINET database. 
TABle 2: Distribution of SAmple by TopiX-17 Series Sector Code

\begin{tabular}{|c|c|c|c|}
\hline Code & Category & No. & $\%$ \\
\hline 1 & Foods & 49 & 4.31 \\
\hline 2 & Energy Resources & 10 & 0.88 \\
\hline 3 & Construction \& Materials & 111 & 9.75 \\
\hline 4 & Raw Materials \& Chemicals & 123 & 10.81 \\
\hline 5 & Pharmaceutical & 20 & 1.76 \\
\hline 6 & Automobiles \& Transportation Equipment & 53 & 4.66 \\
\hline 7 & Steel \& Nonferrous Metals & 50 & 4.39 \\
\hline 8 & Machinery & 87 & 7.64 \\
\hline 9 & Electric Appliances \& Precision Instruments & 124 & 10.9 \\
\hline 10 & IT \& Services, Others & 157 & 13.8 \\
\hline 11 & Electric Power \& Gas & 11 & 0.97 \\
\hline 12 & Transportation \& Logistics & 47 & 4.13 \\
\hline 13 & Commercial \& Wholesale Trade & 91 & 8.00 \\
\hline 14 & Retail Trade & 95 & 8.35 \\
\hline 15 & Banks & 57 & 5.01 \\
\hline 16 & Financials excluding Banks & 24 & 2.11 \\
\hline \multirow[t]{2}{*}{17} & Real Estate & 29 & 2.55 \\
\hline & Total & 1,138 & 100.00 \\
\hline
\end{tabular}

\section{Empirical Results}

\subsection{Descriptive statistics}

Table 3 presents the descriptive statistics of the sample firms' characteristics before and after the adoption of XBRL. This table provides the median, mean, and t-stat mean differences of the five measures for the information environment (ERV, ACAR, $\triangle$ STDDEVRET, ASPREAD, and AVOL) and CONTROLS. If the adoption of XBRL allows users to compare XBRL-tagged data across various organizations more effectively than before, we predict an improvement in the information environment through the reduction of information asymmetry. 
TABLE 3: DESCRIPTIVE STATISTICS

\begin{tabular}{|c|c|c|c|c|c|c|c|}
\hline & \multicolumn{3}{|c|}{$\begin{array}{l}\text { Pre-XBRL }(n=1,138) \\
\end{array}$} & \multicolumn{3}{|c|}{ Post-XBRL $(\mathrm{n}=1,138)$} & \multirow{2}{*}{$\begin{array}{c}\text { Post - Pre (Mean) } \\
\text { t-value }\end{array}$} \\
\hline & Median & Mean & S.D. & Median & Mean & S.D. & \\
\hline ERV & 0.036 & 0.043 & 0.033 & 0.037 & 0.044 & 0.031 & 0.630 \\
\hline ACAR & 0.018 & 0.025 & 0.025 & 0.018 & 0.024 & 0.024 & -0.333 \\
\hline$\triangle \mathrm{STDEVRET}$ & 0.000 & 0.000 & 0.009 & -0.002 & -0.003 & 0.010 & $-6.264 * * *$ \\
\hline ASPREAD & -0.088 & 0.059 & 0.882 & -0.410 & -0.320 & 0.554 & $-12.267 * * *$ \\
\hline AVOL & -0.392 & 0.392 & 9.418 & -0.292 & 0.115 & 2.920 & -0.947 \\
\hline XBRL & 0.000 & 0.000 & 0.000 & 1.000 & 1.000 & 0.000 & - \\
\hline SIZE & 24.504 & 24.721 & 1.489 & 24.274 & 24.451 & 1.474 & $-4.353 * * *$ \\
\hline MB & 1.038 & 1.306 & 1.107 & 0.881 & 1.088 & 0.952 & $-5.031 * * *$ \\
\hline EPRATIO & 0.058 & 0.042 & 0.137 & 0.028 & -0.051 & 0.304 & $-9.462 * * *$ \\
\hline LEV & 0.130 & 0.160 & 0.136 & 0.140 & 0.176 & 0.146 & $2.628 * * *$ \\
\hline LOSS & 0.000 & 0.093 & 0.291 & 0.000 & 0.335 & 0.472 & $14.705 * * *$ \\
\hline TECH & 0.000 & 0.138 & 0.345 & 0.000 & 0.138 & 0.345 & - \\
\hline GOV & 0.108 & 0.139 & 0.118 & 0.084 & 0.117 & 0.109 & $-4.625 * * *$ \\
\hline RETVAR & 0.025 & 0.026 & 0.008 & 0.037 & 0.037 & 0.010 & $30.118 * * *$ \\
\hline NEGCAR & 0.000 & 0.435 & 0.496 & 0.000 & 0.437 & 0.496 & 0.085 \\
\hline CAAR & 0.100 & 0.137 & 0.129 & 0.122 & 0.160 & 0.157 & $3.751 * * *$ \\
\hline
\end{tabular}

Note: ${ }^{* * * *}$ indicates significance at the $1 \%$ level.

Among the five measures, we find a significant decrease in $\triangle$ STDDEVRET and ASPREAD after the adoption of XBRL. These results are consistent with the notion that the introduction of XBRL tends to decrease information asymmetry, although we find no significant difference in ERV, ACAR, or AVOL. ${ }^{21}$

Among the control variables, SIZE, MB, EPRATIO, LEV, LOSS, GOV, RETVAR, and CAAR are significantly different between the pre-XBRL and post-XBRL periods at the 1 percent level. We note that the means of the variables related to the financial health of the firms deteriorate in the post-XBRL period, as observed from the lower EPRATIO and the higher LEV and LOSS. Similarly, SIZE, MB, and GOV decrease in the post-XBRL period and differ at the 1 percent significance level. The deterioration of the financial health and governance of firms may be partially attributed to the 2008 financial crisis, which had a huge negative impact on firms and stock markets. Lastly, RETVAR and CAAR increase in the post-XBRL period and differ at the 1 percent significance level.

Table 4 provides the Pearson correlation matrix among the variables used in the regression. The highest correlation among the independent variables is 0.622 , which is the correlation between SIZE and GOV. The second highest correlation is 0.525 , which is the correlation

\footnotetext{
${ }^{21}$ It is noteworthy that the standard deviation of AVOL in the pre-adoption period is too high compared to that reported in the previous studies, including Miller (2010). We regard this high S.D. as caused by the market turmoil related to the subprime loan problem in 2008. One might argue that not only AVOL but other market variables may also have been affected by subprime loan problems. However, we think that it is natural to believe that the volume data would have been affected by the turmoil to a greater extent than the other variables, because the former reflects both buying and selling behavior while the latter reflects only the net behavior (return or spread). We will discuss the effect of this high S.D. in subsection 4.2.
} 
TABLE 4: PEARSON CORRELATION MATRIX FOR EXPLANATORY VARIABLES

\begin{tabular}{|c|c|c|c|c|c|c|c|c|c|c|}
\hline & XBRL & SIZE & MB & EPRATIO & LEV & LOSS & TECH & GOV & RETVAR & NEGCAR \\
\hline SIZE & -0.091 & & & & & & & & & \\
\hline MB & -0.105 & 0.237 & & & & & & & & \\
\hline EPRATIO & -0.195 & 0.155 & 0.062 & & & & & & & \\
\hline LEV & 0.055 & 0.148 & 0.058 & -0.085 & & & & & & \\
\hline LOSS & 0.295 & -0.174 & -0.110 & -0.548 & 0.103 & & & & & \\
\hline TECH & 0.000 & -0.077 & 0.183 & 0.034 & -0.063 & -0.044 & & & & \\
\hline GOV & -0.097 & 0.622 & 0.144 & 0.071 & -0.015 & -0.120 & -0.012 & & & \\
\hline RETVAR & 0.525 & -0.023 & 0.102 & -0.295 & 0.126 & 0.299 & -0.069 & 0.074 & & \\
\hline NEGCAR & 0.002 & 0.073 & 0.050 & -0.022 & 0.085 & 0.008 & -0.056 & 0.036 & -0.021 & \\
\hline CAAR & 0.079 & -0.174 & 0.067 & -0.169 & -0.008 & 0.142 & 0.012 & -0.052 & 0.234 & 0.104 \\
\hline
\end{tabular}

TABLE 5: CORRELATION WITH DEPENDENT VARIABLES

\begin{tabular}{|c|c|c|c|c|c|c|}
\hline & ERV & ACAR & $\Delta$ STDDEVRET & ASPREAD & AVOL & VIF \\
\hline XBRL & 0.013 & -0.007 & -0.128 & -0.249 & -0.020 & 1.130 \\
\hline SIZE & -0.095 & -0.055 & 0.136 & -0.060 & -0.062 & 1.296 \\
\hline MB & 0.133 & 0.062 & -0.027 & 0.006 & -0.004 & 1.025 \\
\hline EPRATIO & -0.121 & -0.097 & 0.088 & 0.011 & -0.030 & 1.121 \\
\hline LEV & 0.047 & 0.054 & -0.037 & -0.034 & 0.038 & 1.006 \\
\hline LOSS & 0.142 & 0.075 & -0.107 & -0.023 & 0.071 & 1.144 \\
\hline TECH & 0.042 & 0.008 & -0.044 & -0.034 & 0.013 & 1.005 \\
\hline GOV & -0.010 & 0.001 & 0.109 & -0.037 & -0.053 & 1.220 \\
\hline RETVAR & 0.251 & 0.163 & -0.082 & -0.179 & -0.004 & 1.200 \\
\hline NEGCAR & -0.096 & -0.090 & -0.024 & -0.053 & -0.032 & 1.001 \\
\hline CAAR & 0.281 & 0.256 & -0.143 & 0.093 & 0.140 & 1.011 \\
\hline
\end{tabular}

between XBRL and RETVAR. Despite the relatively high correlations in these two areas, the rest of the correlations among the independent variables are below 0.5. The Variance Inflation Factor (VIF) is also calculated to confirm the absence of multicollinearity (Table 5). ${ }^{22} \mathrm{~A}$ general guide is that multicollinearity is high when VIF $>5$. As all the calculated VIF values are below 2, the absence of multicollinearity could be confirmed.

\subsection{Regression results}

Table 6 shows the multivariate regression results for the effects of XBRL on the information environment in the Japanese market. Models 1 to 5 use ERV, ACAR, $\triangle$ STDDEVRET, ASPREAD, and AVOL as dependent variables, respectively, based on equations (10) to (14). For Models 1 to 4, the coefficients of XBRL are significantly negative at the 1 percent level, although the coefficient of XBRL is not significantly different from zero for Model 5. The

\footnotetext{
${ }^{22}$ This factor is calculated with a three-step process. The first step involves running an ordinary least regression on each control variable as a function of all other explanatory variables to obtain a coefficient of determination of the regression equation. The second step involves calculating the VIF factor for each control variable using the formula $V I F=\frac{1}{1-R^{2}}$. The final step is to analyze the magnitude of multicollinearity by considering the size of the VIF values.
} 


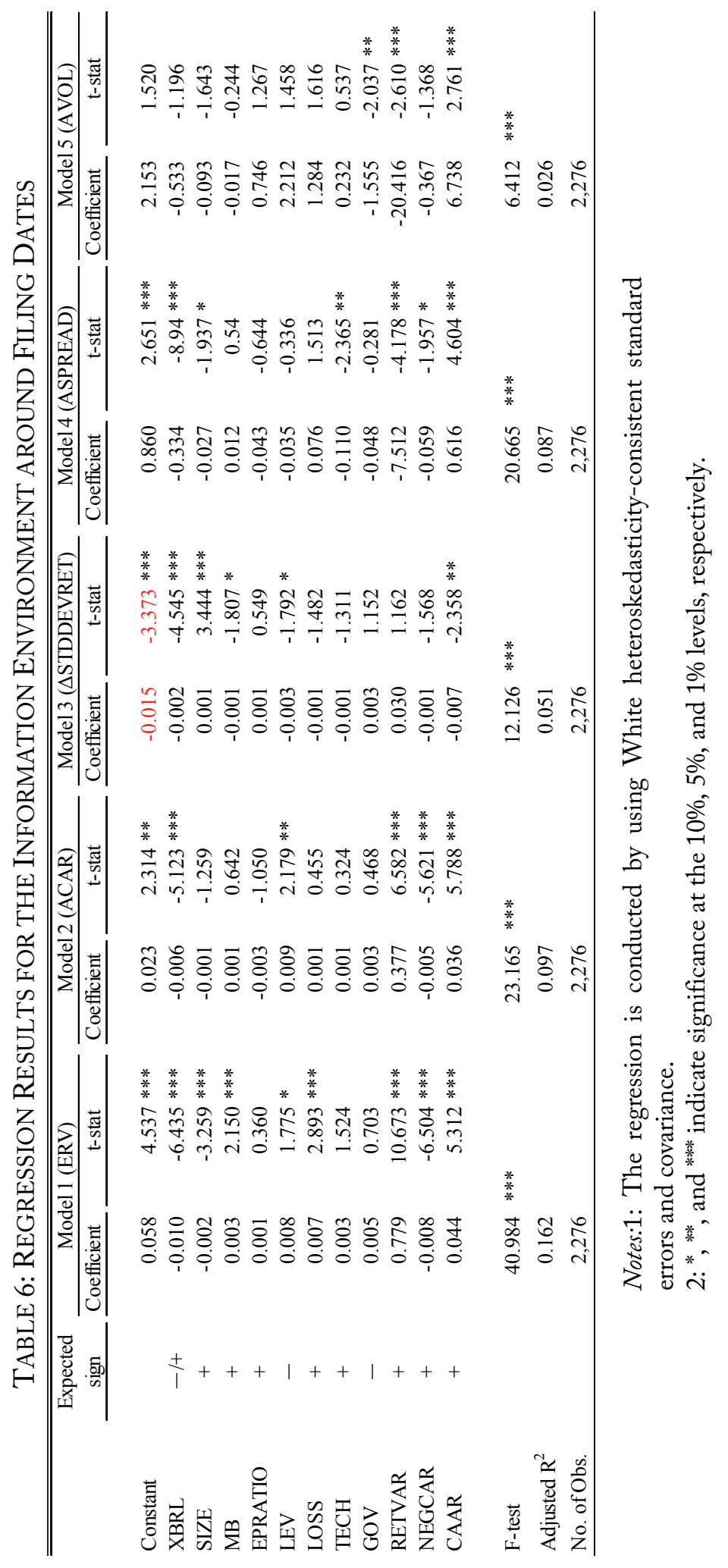


TABLE 7: REGRESSION RESULTS WITHOUT OUTLIERS

\begin{tabular}{|c|c|c|c|c|c|c|c|c|c|c|c|}
\hline & \multirow{2}{*}{$\begin{array}{c}\text { Expected } \\
\text { sign }\end{array}$} & \multicolumn{2}{|c|}{ Model 1 (ERV) } & \multicolumn{2}{|c|}{ Model 2 (ACAR) } & \multicolumn{2}{|c|}{ Model $3(\triangle$ STDDEVRET) } & \multicolumn{2}{|c|}{ Model 4 (ASPREAD) } & \multicolumn{2}{|c|}{ Model 5 (AVOL) } \\
\hline & & Coefficient & t-stat & Coefficient & t-stat & Coefficient & t-stat & Coefficient & t-stat & Coefficient & t-stat \\
\hline Constant & & 0.040 & $3.893 * * *$ & 0.022 & $2.453 * *$ & -0.011 & $-3.380 * * *$ & 0.505 & $1.681 *$ & 0.314 & 0.731 \\
\hline XBRL & $-/+$ & -0.009 & $-7.274 * * *$ & -0.005 & $-5.148 * * *$ & -0.002 & $-4.863 * * *$ & -0.291 & $-8.651 * * *$ & 0.064 & 1.311 \\
\hline SIZE & + & -0.001 & $-2.099 * *$ & -0.000 & -1.094 & 0.000 & $3.138 * * *$ & -0.014 & -1.109 & -0.023 & -1.256 \\
\hline MB & + & 0.001 & 1.371 & -0.000 & -0.454 & -0.000 & -0.856 & -0.001 & -0.072 & 0.030 & 1.004 \\
\hline EPRATIO & + & 0.004 & $2.334 * *$ & 0.000 & 0.169 & -0.001 & $-2.034 * *$ & 0.018 & 0.451 & 0.109 & 1.588 \\
\hline LEV & - & 0.004 & 0.971 & 0.006 & $1.949 *$ & -0.002 & $-1.737 *$ & -0.050 & -0.524 & 0.385 & $2.750 * * *$ \\
\hline LOSS & + & -0.002 & -0.625 & -0.004 & -1.632 & 0.001 & 0.772 & -0.079 & -1.249 & 0.042 & 0.393 \\
\hline TECH & + & 0.003 & $2.089 * *$ & -0.001 & -0.414 & -0.000 & -0.474 & -0.106 & $-2.694 * * *$ & -0.024 & -0.406 \\
\hline GOV & - & 0.006 & 1.081 & 0.005 & 1.111 & 0.004 & $2.034 * *$ & -0.035 & -0.224 & -0.287 & -1.269 \\
\hline RETVAR & + & 0.729 & $12.479 * * *$ & 0.354 & $6.813 * * *$ & 0.026 & 1.185 & -5.820 & $-3.583 * * *$ & -3.436 & -1.454 \\
\hline NEGCAR & + & 0.028 & $5.908 * * *$ & 0.024 & $5.970 * * *$ & -0.003 & $-1.820 *$ & 0.427 & $4.050 * * *$ & 1.268 & $6.634 * * *$ \\
\hline CAAR & + & -0.006 & $-6.068 * * *$ & -0.005 & $-5.705 * * *$ & -0.000 & -1.124 & -0.044 & -1.603 & -0.105 & $-2.624 * * *$ \\
\hline F-test & & 36.658 & $* * *$ & 19.096 & $* * *$ & 10.513 & $* * *$ & 17.669 & $* * *$ & 10.789 & $* * *$ \\
\hline Adjusted $\mathrm{R}^{2}$ & & 0.150 & & 0.082 & & 0.045 & & 0.076 & & 0.046 & \\
\hline No. of Obs. & & 2,230 & & 2,230 & & 2,230 & & 2,230 & & 2,230 & \\
\hline
\end{tabular}

Notes: 1: The regression is conducted by using White heteroskedasticity-consistent standard errors and covariance.

$2:{ }^{*}, * *$ and ${ }^{* * *}$ indicate statistical significance at the $10 \%, 5 \%$, and $1 \%$ levels, respectively.

significantly negative correlation between XBRL and the four measures (ERV, ACAR, $\triangle$ STDDEVRET, and ASPREAD) are consistent with the notion that XBRL adoption improves the information environment by reducing information asymmetry.

Our result for Models 1 to 4 shows similar benefits from the adoption of XBRL as those reported in prior studies, including those by Tan and Shon (2009), Yoon et al. (2011), and Kim et al. (2012). However, our result for Model 5 supports neither the notion that investors have incentives to trade more actively in an XBRL environment nor the results of Blankespoor et al. (2014), which show a decrease of AVOL after the adoption of XBRL. ${ }^{23}$

There are possibly three reasons to explain why our result for AVOL is not consistent with that of prior studies. First, as reported in Table 3, the standard deviation of AVOL is quite large in the pre-adoption period. This could have been caused by the market turmoil related to the subprime loan problems. This high volatility in AVOL may have caused the insignificant results in our study. Second, AVOL may not always reflect information asymmetry among investors but a diversified interpretation of the news (Kim and Verrecchia 1991, 1997; Bamber et al. 2011). In other words, it may not be appropriate to use AVOL as a measure of information asymmetry, as investors' interpretation of the news may differ largely during the period of financial turmoil. Third, outliers may have caused the negative and insignificant coefficient on AVOL.

To check the third possibility, we follow Kim et al. (2012) and Blankespoor et al. (2014) by winsorizing all five dependent variables at $1 \%$ and $99 \%$ to remove the effect of outliers and conduct the same regressions. The results are shown in Table 7; as may be seen, they are quite similar to those reported in Table 6. However, we note that the coefficient on AVOL becomes

${ }^{23} \mathrm{We}$ also note that the adoption of XBRL brings about benefits similar to those of the Regulation Fair Disclosure (Reg FD) mandate enacted in the U.S. in 2000. Our results show that the XBRL mandate in Japan helps to reduce ACAR and ERV in the post-XBRL period, as seen from the negative coefficient of XBRL in both regressions. This is consistent with the results for the impact of the mandate of Reg FD (Heflin et al. 2003; Bailey et al. 2003). 
positive. Although it is not significant, Table 7 indicates the possibility that outliers may have caused negative coefficient on AVOL.

The results for control variables are mixed. First, the coefficients of SIZE are significantly negative for Models 1 and 4, significantly positive for Model 3, and insignificant for Models 2 and 5 . In other words, our results are mixed with regard to the size effect because the results for Models 1 and 4 are consistent with our prediction that larger firms tend to have lower information asymmetry, while those of other results are not. We note that Blankespoor et al. (2014) also provide insignificant results for the ASPREAD used in Model 2. They also report a significantly negative size effect on AVOL using a large trade volume but insignificant size effect on AVOL using a small trade volume. This may suggest that our insignificant result for Model 5 comes from the fact that we combine both large and small trading volumes.

As for the effect of potential growth on information asymmetry, the results for $\mathrm{MB}$ are also mixed, with a significantly positive coefficient for Model 1, a significantly negative coefficient for Model 3, and insignificant coefficients for Models 2, 4, and 5. The result for Model 1 is consistent with our prediction, while those of other results are not. We note that Kim et al. (2012) provide insignificant results for $\triangle$ STDDEVRET. Blankespoor et al. (2014) also report a significantly negative size effect on AVOL using a large trade volume but an insignificant size effect on AVOL using a small trade volume. Thus, the relationship between $\mathrm{MB}$ and $\triangle$ STDDEVRET or AVOL is not stable in prior studies, either. In addition, the coefficients of EPRATIO are not different from zero for any of the models.

The results for LEV are mixed, with significantly positive coefficients for Models 1 and 2, a significantly negative coefficient for Model 3, and insignificant coefficients for Models 4 and 5 . The result for Model 3 is consistent with our expectations, while the other results are not consistent with our expectations. This result is not very surprising considering the fact that Kim et al. (2012) reports only one significantly negative coefficient of EV among five regression models. The coefficient of LOSS is significantly positive for Model 1, while it is insignificant for the other four models.

With regard to the industry effect, the coefficient of TECH is significantly negative only for Model 4, which is not consistent with our prediction. Regarding the effect of the shareholder composition, the coefficient of GOV is significantly negative only for Model 5, which is not consistent with our prediction, while it is insignificant for the other four models. In other words, we do not find consistent industry effects.

The remaining variables also provide mixed results: The coefficients of RETVAR are significantly positive for Models 1 and 2, insignificant for Model 3, and significantly negative for Models 4 and 5. The results for Models 1 to 3 are consistent with those of Kim et al. (2012), which report significantly positive coefficients for ERV and ACAR but insignificant coefficients for $\triangle$ STDDEVRET. The coefficients of NEGCAR are significantly negative for Models 1,2 , and 4 and insignificant for Models 3 and 5. This result is not surprising, as Kim et al. (2012) report insignificant coefficients on NEGCAR for four regression models. The coefficients of CAAR are significantly positive for Models 1, 2, 4, and 5 and insignificant for Model 3. This result is not surprising, as Kim et al. (2012) report only one significantly positive coefficient on CAAR among four regression models.

As in the case of prior studies, we do not obtain consistent results for the control variables. However, four of the five models in our regression analysis show the reduction of information asymmetry and then the improvement of the information environment in the Japanese market. 
TABLE 8: REGRESSION RESULTS FOR THE INFORMATION ENVIRONMENT AROUND FILING DATES (WITHOUT FIRMS IN THE FINANCIAL INDUSTRY)

\begin{tabular}{|c|c|c|c|c|c|c|c|c|c|c|c|}
\hline & \multirow{2}{*}{$\begin{array}{l}\text { Expected } \\
\text { sign }\end{array}$} & \multicolumn{2}{|c|}{ "Model 1 (ERV) } & \multicolumn{2}{|c|}{ Model 2 (ACAR) } & \multicolumn{2}{|c|}{ "Model 3 ( $\triangle$ STDDEVRET) } & \multicolumn{2}{|c|}{ "Model 4 (ASPREAD) } & \multicolumn{2}{|c|}{ "Model 5 (AVOL) } \\
\hline & & Coefficient & t-stat & Coefficient & t-stat & Coefficient & t-stat & Coefficient & t-stat & Coefficient & t-stat \\
\hline Constant & & 0.043 & $3.018 * * *$ & 0.014 & 1.233 & -0.018 & $-3.729 * * *$ & 0.609 & $1.732 *$ & 2.086 & 1.235 \\
\hline XBRL & $-/+$ & -0.011 & $-6.560 * * *$ & -0.006 & $-5.005 * * *$ & -0.002 & $-4.034 * * *$ & -0.333 & $-8.610 * * *$ & -0.533 & -1.146 \\
\hline SIZE & + & -0.001 & $-1.801 *$ & 0.000 & -0.229 & 0.001 & $3.757 * * *$ & -0.014 & -0.947 & -0.091 & -1.300 \\
\hline MB & + & 0.003 & $1.940 *$ & 0.001 & 0.619 & -0.001 & $-1.760 *$ & 0.005 & 0.237 & -0.016 & -0.220 \\
\hline EPRATIO & + & 0.002 & 0.446 & -0.003 & -1.126 & 0.001 & 0.677 & -0.039 & -0.559 & 0.857 & 1.343 \\
\hline LEV & - & 0.004 & 0.848 & 0.006 & 1.313 & -0.004 & $-2.227 * *$ & -0.164 & -1.426 & 2.299 & 1.336 \\
\hline LOSS & + & 0.008 & $3.152 * * *$ & 0.001 & 0.787 & -0.001 & $-1.143 * * *$ & 0.106 & $1.967 * *$ & 1.395 & $1.649 *$ \\
\hline $\mathrm{TECH}$ & + & 0.003 & 1.367 & 0.000 & 0.191 & -0.001 & -1.439 & -0.121 & $-2.572 * *$ & 0.227 & 0.525 \\
\hline GOV & - & -0.002 & -0.212 & -0.001 & -0.172 & 0.001 & 0.366 & -0.145 & -0.775 & -1.655 & $-2.221 * *$ \\
\hline RETVAR & + & 0.796 & $10.565 * * *$ & 0.374 & $6.345 * * *$ & 0.034 & 1.279 & -7.804 & $-4.220 * * *$ & -21.628 & $-2.576 * *$ \\
\hline NEGCAR & + & -0.008 & $-6.289 * * *$ & -0.005 & $-5.472 * * *$ & -0.001 & -1.603 & -0.056 & $-1.777 *$ & -0.361 & -1.279 \\
\hline CAAR & + & 0.045 & $5.255 * * *$ & 0.037 & $5.746 * * *$ & -0.008 & $-2.315 * *$ & 0.660 & $4.805 * * *$ & 6.941 & $2.749 * * *$ \\
\hline F-test & & 37.984 & $* * *$ & 21.676 & $* * *$ & 10.787 & $* * *$ & 19.812 & $* * *$ & 6.096 & $* * *$ \\
\hline Adjusted $\mathrm{R}^{2}$ & & 0.161 & & 0.097 & & 0.048 & & 0.089 & & 0.026 & \\
\hline No. of Obs. & & 2,114 & & 2,114 & & 2,114 & & 2,114 & & 2,114 & \\
\hline
\end{tabular}

Notes: 1: The regression is conducted by using White heteroskedasticity-consistent standard errors and covariance.

$2:{ }^{*}, *$, and ${ }^{* *}$ indicate significance at the $10 \%, 5 \%$, and $1 \%$ levels, respectively.

Although the coefficient on AVOL is negative and insignificant, this could have been due to outliers. In the next section, we conduct two sensitivity analyses to guarantee the robustness of our main results regarding measures of the financial information environment.

\section{Sensitivity Analysis}

In this last section, we conduct two sensitivity analyses. We note that the stock market was very volatile for the period including the implementation of XBRL because of the financial crisis in 2008. The inclusion of firms in the financial industry may bias our results because those firms are likely to have suffered a great deal during our test period. We rerun the regression of all the models in Table 8 after eliminating Banks and Financial Industry firms (codes 15 and 16 in Table 2). After eliminating these firms, our results are qualitatively similar to those in Table 5. Our main coefficients of XBRL remain negative and significant at the 1 percent level for Models 1 to 4 .

Second, we try different periods for comparison. Specifically, we collect data for 2 years prior to the adoption of XBRL by the FSA. We use the same research design to carry out the multiple regression analyses to verify whether the results are the same. In this context, we use January 1 , 2007 to June 30, 2007 as the pre-XBRL period and January 1, 2008 to June 30, 2008 as the postXBRL period. Table 9 shows the results of the multiple regression analysis. The coefficients of XBRL are significantly positive for Models 2 and 4, insignificant for Models 1 and 5, and significantly negative for Model 3 . These results are contrary to our original results in Table 5, which indicates that XBRL adoption reduces information asymmetry. Thus, we can conclude that no consistent market-wide effects are observed that help to reduce information asymmetry in the TSE during this different period. This sensitivity analysis supports the notion that the improvement of the information environment can be attributed to the adoption of XBRL. 
TABLE 9: REGRESSION RESULTS FOR THE INFORMATION ENVIRONMENT AROUND FILING DATES BASED ON ALTERNATIVE PRE-AND POST-XBRL PERIODS

\begin{tabular}{|c|c|c|c|c|c|c|c|c|c|c|c|}
\hline & \multirow{2}{*}{$\begin{array}{c}\text { Expected } \\
\text { sign } \\
\end{array}$} & \multicolumn{2}{|c|}{ Model 1 (ERV) } & \multicolumn{2}{|c|}{ Model 2 (ACAR) } & \multicolumn{2}{|c|}{ Model 3 ( $\triangle$ STDDEVRET) } & \multicolumn{2}{|c|}{ Model 4 (ASPREAD) } & \multicolumn{2}{|c|}{ Model 5 (AVOL) } \\
\hline & & Coefficient & t-stat & Coefficient & t-stat & Coefficient & t-stat & Coefficient & t-stat & Coefficient & t-stat \\
\hline Constant & & 0.021 & 1.441 & 0.001 & 0.100 & -0.026 & $-5.500 * * *$ & 0.564 & 1.302 & -0.530 & -0.641 \\
\hline XBRL & $-1+$ & 0.003 & 1.430 & 0.004 & $1.943 *$ & -0.002 & $-4.054 * * *$ & 0.291 & $6.100 * * *$ & -0.091 & -0.530 \\
\hline SIZE & + & -0.001 & -0.937 & 0.000 & 0.038 & 0.001 & $5.744 * * *$ & -0.028 & -1.527 & 0.033 & 0.935 \\
\hline MB & + & 0.003 & $2.123 * *$ & 0.002 & 1.552 & -0.001 & $-2.524 * *$ & 0.005 & 0.182 & 0.009 & 0.218 \\
\hline EPRATIO & + & 0.000 & -1.023 & 0.000 & 0.360 & 0.000 & $-1.650 *$ & 0.000 & 0.143 & 0.000 & -1.286 \\
\hline LEV & - & 0.006 & 1.027 & 0.008 & 1.540 & -0.003 & -1.506 & 0.134 & 0.913 & 0.481 & 1.447 \\
\hline LOSS & + & 0.006 & 1.484 & 0.003 & 1.026 & -0.002 & $-2.354 * *$ & 0.161 & 1.615 & 0.895 & 0.985 \\
\hline TECH & + & -0.002 & -0.720 & -0.001 & -0.556 & -0.001 & -1.456 & -0.095 & -1.615 & -0.359 & $-2.644 * * *$ \\
\hline GOV & - & -0.009 & -1.143 & 0.000 & -0.026 & 0.002 & 0.841 & 0.044 & 0.193 & -1.372 & $-2.246 * *$ \\
\hline RETVAR & + & 0.885 & $6.365 * * *$ & 0.389 & $3.372 * * *$ & 0.090 & $2.031 * *$ & -10.653 & $-3.402 * * *$ & -29.159 & $-1.798 *$ \\
\hline NEGCAR & + & -0.004 & $-3.118 * * *$ & -0.004 & $-3.541 * * *$ & -0.001 & -1.120 & -0.035 & -0.898 & -0.207 & -1.541 \\
\hline CAAR & + & 0.071 & $5.405 * * *$ & 0.055 & $4.336 * * *$ & -0.001 & -0.141 & 0.983 & $4.542 * * *$ & 6.158 & $2.138 * *$ \\
\hline F-test & & 40.549 & $* * *$ & 26.307 & $* * *$ & 8.978 & $* * *$ & 9.148 & $* * *$ & 8.682 & $* * *$ \\
\hline Adjusted $\mathrm{R}^{2}$ & & 0.206 & & 0.142 & & 0.050 & & 0.051 & & 0.048 & \\
\hline No. of Obs. & & 1,678 & & 1,678 & & 1,678 & & 1,678 & & 1,678 & \\
\hline
\end{tabular}

Notes: 1: The regression is conducted by using White heteroskedasticity-consistent standard errors and covariance.

$2:{ }^{*},{ }^{* *}$, and ${ }^{* * *}$ indicate statistical significance at the $10 \%, 5 \%$, and $1 \%$ levels, respectively.

\section{Concluding Remarks}

In 2008, the Japanese FSA mandated that firms be required to submit their annual securities reports to the EDINET in the XBRL format. The FSA believes that this new search-facilitating technology will enhance the transparency and quality of business reporting and improve the information environment in the Japanese market. However, given the non-trivial implementation and learning costs involved in the adoption of XBRL, whether the XBRL-based disclosure improves the information environment is an empirical question. In the present study, we investigate the effects of the mandatory XBRL requirement on the information environment around the annual securities filing by using data on firms listed in the first section of the TSE.

Our regression results provide evidence consistent with the notion that XBRL adoption improves the information environment in the Japanese market. This can be observed from the highly significant and negative associations between XBRL adoption and event returns volatility, absolute cumulative abnormal returns, changes in the standard deviation of returns, and abnormal bid-ask spread after controlling for firm-specific characteristics. Our findings suggest that XBRL disclosures have the potential to reduce information asymmetry through improved accessibility and transparency. These findings are robust to a sensitivity analysis excluding financial firms.

We acknowledge that our study is not exempt from limitations. In particular, we focus on the effect of XBRL adoption on the information asymmetry among investors. However, XBRL should influence other stakeholders including filers and regulators. Future research should be needed to investigate the more comprehensive impacts of XBRL adoption on various stakeholders. 


\section{REFERENCES}

AJINKYA, B., S. BHOJARJ, AND P. SENGUPTA. 2005. The association between outside directors, institutional investors and the properties of management earnings forecasts. Journal of Accounting Research 43 (3): 343-376.

BAMBER, L. S., O. E. BARRON, AND D. E. STEVENS. 2011. Trading volume around earnings announcements and other financial reports: Theory, research design, empirical evidence, and directions for future research. Contemporary Accounting Research 28 (2): 431-471.

BAILEY, W., H. LI, C. MAO, AND R. ZHONG. 2003. Regulation fair disclosure and earnings information: Market, analyst, and corporate responses. Journal of Finance 58 (6): 2487-2514.

BARTLEY, J., A. Y. S. CHEN, E. TAYLOR. 2011. A comparison of XBRL filings to corporate 10-Ks evidence from the voluntary filing program. Accounting Horizons 25 (2): 227-245.

BEAVER, W. H. 1968. The information content of annual earnings announcements. Journal of Accounting Research 6: 67-92.

BlankespoOr, E., B. P. Miller, AND H. D. White. 2014. Initial evidence on the market impact of the XBRL mandate. Review of Accounting Studies 20 (1): 1-36.

BOnSON, E., V. CORTIJO, AND T. EsCOBAR. 2009. Towards the global adoption of XBRL using International Financial Reporting Standards (IFRS). International Journal of Accounting Information Systems 10 (1): 46-60.

CORWIN, S. A., AND P. SCHULTZ. 2012. A simple way to estimate Bid-Ask spreads from daily high and low prices. Journal of Finance 67 (2): 719-760.

Debreceny, R., S. Farewell, M. Piechocki, C. Felden, And A. Graning. 2010. Does it add up? Early evidence on the data quality of XBRL filings to the SEC. Journal of Accounting and Public Policy 29 (3): 296-306.

DZINKOWSKI R. 2008. Do you speak XBRL? CA Magazine December 2008.

EFENDI, J., J. D. PARK, AND C. SUBRAMANIAM. 2010. Do XBRL reports have incremental information content? - An empirical analysis. Working Paper, Available at SSRN: http://ssrn.com/abstract=1671723.

FRANCIS, J., N. DHANANJAY, AND X. WANG. 2006. Re-examining the effects if regulation fair disclosure using foreign listed firms to control for concurrent shocks. Journal of Accounting and Economics 41 (3): 271-292.

Heflin, F., K. R. Subramanyam, AND Y. ZHANG. 2003. Regulation FD and the financial information environment: Early evidence. The Accounting Review 78 (1): 1-37.

HENSELMANN K., AND E. SCHERR. 2012. Content analysis of XBRL filings as an efficient supplement of bankruptcy prediction? Working Paper, Friedrich-Alexander University of Erlangen-Nürnberg, School of Business and Economics.

Hodge, F. D., J. J. Kennedy, AND L. A. MAines. 2004. Does search-facilitating technology improve the transparency of financial reporting? The Accounting Review 79 (3): 687-703.

Hoffman, C., And L. A. Watson. 2010. XBRL for Dummies. For Dummies.

ISARG. 2011. The future of XBRL in Europe: Impetus, institutions and interrelationships. Proceeding of ICAEW and University of Birmingham (ISARG) Workshop, Available at: http://www.icaew.com/ / media/Files/About-ICAEW/What-we-do/thought-leadership/the-future-of-xbrl-in-europe-finalsummary-for-release.pdf.

Kagaya, T., T. NAKANO, Y. Matsumoto, AND Y. MACHIDA. 2011. Evaluation and direction for 
improvement of quarterly reporting (Shihanki jouhou kaiji seido no hyoka to kaizen houkoku). Discussion Paper, RIETI. (in Japanese)

KIM, J. W., J. LIM, AND W. G. NO. 2012. The effect of first wave mandatory XBRL reporting across the financial information environment. Journal of Information Systems, 26 (1): 127-153.

KIM, O., AND R. E. VERRECHIA. 1991. Trading volume and price reactions to public announcements. Journal of Accounting Research 29 (2): 302-321.

KIM, O., AND R. E. VERRECHIA. 1997. Pre-announcement and event-period private information. Journal of Accounting and Economics 24 (3): 395-419.

KOTHARI, S. P., X. LI, AND J. E. SHORT. 2009. The effect of disclosures by management, analysts, and business press on cost of capital, return volatility, and analyst forecasts: A study using content analysis. The Accounting Review 84 (5): 1639-1670.

MacKinlay, A. C. 1997. Event studies in economics and finance. Journal of Economic Literature 35: 13-39.

MilleR, B. 2010. The effects of reporting complexity on small and large investor trading. The Accounting Review 85 (6): 2107-2143.

Morgan, J. 2009. Companies prepare for XBRL rules. Money Management Executive, Available at: http://www.mmexecutive.com/issues/2009_10/190893-1.html.

PENG, E. Y., J. SHON, AND C. TAN. 2011. XBRL and accruals: Empirical evidence from China. Accounting Perspectives 10 (2): 109-138.

PINSKER, R., AND S. LI. 2008. Costs and benefits of XBRL adoption: Early evidence. Communications of the ACM 51 (3): 47-50.

PINSKER, R., AND P. WHEELER. 2009. Nonprofessional investors' perceptions of the efficiency and effectiveness of XBRL-enabled financial statement analysis and of firms providing XBRL-formatted information. International Journal of Disclosure and Governance 6 (3): 241-261.

Premuroso, R. F., AND S. BHATTACHARYA. 2008. Do early and voluntary filers of financial information in XBRL format signal superior corporate governance and operation performance? International Journal of Accounting Information Systems 9 (1): 1-20.

RoOHAni, S., X. Zhao, E. A. CAPOZZOLI, AND B. LAMBERTON. 2010. Analysis of XBRL literature: A decade of progress and puzzle. The International Journal of Digital Accounting Research 10: 131-147.

RoOHAni, S., AND X. ZHEnG. 2011. Determinants of the deficiency of XBRL mandatory filings. Working Paper, Bryant University.

SAKAUE, M. 2011. Introduction of IFRS taxonomy into EDINET system and its issues. Hosei University Keiei Shirin 48 (1): 63-76. (in Japanese)

SAKUTA, A. 2008. Cases of real use in Japan, Paper Presented at the 18th XBRL Conference.

SECURITIES AND EXCHANGE COMMISSION. 2009. Interactive Data to Improve Financial Reporting. Available at: http://www.sec.gov/rules/final/2009/33-9002.pdf.

SKINNER, D. J., AND R. G. SLOAN. 2002. Earnings surprises, growth expectations, and stock returns or don't let an earnings torpedo sink your portfolio. Review of Accounting Studies 7 (2-3): 289-312.

STARR, M. 2012. SEC interview: Inside information. Interactive Business Reporting, 2 (1): 17-20. Available at: http://www.ibr-mag.com/upload/issue/2012/feb/ibr_FEB12_inside_information-p17-20.pdf.

TAN, C., AND J. SHON. 2009. XBRL and its financial reporting benefits: Capital market evidence. Working Paper, Fordham University, New York.

VALENTINETTI, D., M. A. REA. 2011. IFRS Taxonomy and financial reporting practices: The case of 
Italian listed companies. International Journal of Accounting Information Systems 13 (2): 163-180.

WADA, Y. 2006. The bank of Japan. XBRL Case Studies: Showing XBRL in Use. Available at: http://www.xbrl.org/CaseStudies/BoJ_XBRL_06.pdf.

Yoon, H., H. Zo, AND A. P. CigANEK. 2011. Does XBRL adoption reduce information asymmetry? Journal of Business Research 64 (2): 157-163.

YOsHIDA, K. 2008. Tokyo Stock Exchange's XBRL project. Paper Presented at the 18th XBRL Conference.

ZHU, H., AND L. FU. 2009. Towards quality of data standards: Empirical findings form XBRL. ICIS 2009 Proceedings, Available at: http://aisel.aisnet.org/icis2009/66. 


\section{Appendix 1: Setting of Japan}

Japan was an early and active adopter of the XBRL. One of the earliest adopters of XBRL was the NTA, which announced an e-Tax filing system using XBRL 2.0 as the filing format in 2003 and began accepting XBRL 2.1 filings in 2008 (Sakuta 2008). The introduction of XBRL by the NTA also allowed unlisted companies to utilize XBRL. For example, small- and mediumsized companies can reuse their XBRL-based financial statements, which they used for tax filings online to take loans from banks. In February 2006, the Financial Systems and Bank Examination Department of the BOJ developed a new data transfer scheme based upon the latest XBRL technology, Formula Link, to improve the efficiency of gathering data from financial institutions (Wada 2006). According to the BOJ, the introduction of XBRL for monthly balance sheet information has led to a significant reduction in the burden of data validation and other gains in efficiency. In July 2008, the TSE introduced the third generation TDnet server for XBRL production use, at which time provisions of financial data in the XBRL format commenced. Earnings reports and corporate governance reports were submitted in the XBRL format under the timely disclosure policy, which was applicable to approximately 4,000 listed companies at stock exchanges in Japan (Yoshida 2008).

The FSA has an EDINET system, which started its operations in June 2001. The EDINET is an electronic corporate disclosure system under the Financial Instruments and Exchange Act, and all listed companies and investment funds in Japan are required to file their disclosure documents using the system. These submitted corporate disclosure documents are prepared in HTML format and publicly available on the Internet through EDINET. Within this system, a series of procedures ranging from submission, receipt, and public viewing of annual securities reports (yukashoken houkokusho in Japanese) and other disclosure documents are carried out online. These procedures were implemented on paper prior to the introduction of the EDINET system. Thus, EDINET serves as a platform for information disclosure, enabling the prompt disclosure of critical information for investors and issuers and allowing the general public to instantly access corporate information that has been submitted (Takeda 2008).

On March 17, 2008, the FSA launched a new EDINET system in preparation for the adoption of XBRL. All filers are mandated to submit the financial statements included in their annual securities reports, semiannual securities reports, quarterly securities reports and securities registration statements for fiscal years starting in or after April 2008 in the XBRL format. Quarterly securities reports for the first fiscal quarter ending in June 2008 comprised the first filing in the XBRL format. In other words, financial statements in the XBRL format can be retrieved from the EDINET as of the end of June 2008. ${ }^{24}$ These financial statements in the XBRL format are to be prepared using "EDINET Taxonomy" (JP-GAAP taxonomy). Since autumn 2009, the FSA has been conducting research and testing to expand the XBRL's scope of application and upgrade EDINET's functionality. EDINET was scheduled to be upgraded in fiscal 2013.

\footnotetext{
${ }^{24}$ Precisely speaking, financial statements in the XBRL format became available at the EDINET on June 29, 2008. The number of the filers in June 2008 was nine.
} 
Appendix 2: Literature review on the reporting quality of $X B R L$

The reporting quality of XBRL-based financial reports is vital to its success. It is expected that human errors will be minimized as XBRL reduces the need for repetitive data entry (Morgan 2009), which will help to improve both data migration efficiency and accuracy. However, the literature provides evidence that the XBRL reporting still contains deficiencies and incompleteness (Zhu and Fu 2009; Debreceny et al. 2010; Bartley et al. 2011; Roohani and Zheng 2011).

Zhu and Fu (2009) develop metrics to empirically evaluate financial reports created using the XBRL data standards. The use of standard elements and company-specific elements is found to vary substantially across companies. An average company uses 128 elements from the XBRL standard, which defines approximately 2,000 elements, and introduces 64 elements of its own. The completeness and relevancy of data standards affect the interoperability of the data created. However, they show that the XBRL standard has low completeness and relevancy from an individual company's perspective. To the average company, the completeness of the XBRL standard is 66.67 percent and the relevancy of the standard is 6.4 percent.

Debreceny et al. (2010) study one aspect of data quality errors in the computation of related monetary facts in the XBRL filings. Out of 400 filers, they discover that one-quarter have computational errors, half of which are due to inappropriate treatment in the instance documents of the underlying debit/credit assumptions in the taxonomy. An additional quarter of the errors are due to missing or extraneous values in a calculation relationship. Bartley et al. (2011) also find that all 22 companies made errors during the first year of voluntary XBRL filings by examining 22 companies' initial voluntary XBRL 10-K filings. To find the determinants of the deficiency of XBRL mandatory filings, Roohani and Zheng (2011) investigate all the SEC filings from July 2009 to December 2010. They conclude that XBRL-deficient filings tend to have a higher percentage of extensions and are filed by bigger and more complex firms. ${ }^{25} \mathrm{In}$ addition, firms that have considerable experience in XBRL filings are less likely to have major errors. On the contrary, they are more likely to have minor errors.

The reporting quality of XBRL is also related to the issue of whether XBRL taxonomies, which have a crucial role in digital financial reporting by providing a unique set of computerreadable tags to allow the interchange of interactive information, are consistent with the reporting practices (Bonson et al. 2009; Valentinetti and Rea 2011). Bonson et al. (2009) argue that multiple XBRL taxonomies based on different accounting principles contradict the objectives of the standardization, comparability, and reusability of the XBRL information. They evaluate the effectiveness of the IFRS-GP taxonomy that could establish a common ground for international firms and create a platform that would enhance the benefits of XBRL. Valentinetti and Rea (2011) also attempt to verify whether the IFRS taxonomy released by the IFRS Foundation adequately reflects the reporting practices of Italian listed companies. The results reveal a general discrepancy between the financial items disclosed by the firms and the taxonomy tags. Specifically, these findings demonstrate that the financial statement items are more

\footnotetext{
${ }^{25}$ Sakaue (2011) investigates the XBRL data of early adopters of International Financial Reporting Standards (IFRS) taxonomy in Japan and finds that company-specific extended items account for more than 60 percent of the whole in financial statements.
} 
disaggregated than the taxonomy tags, and as such, a loss of detailed information may occur if the taxonomy is applied.

Appendix 3: Variable definitions

\begin{tabular}{ll}
\hline \hline ERV & Arithmetic sum of the absolute values of ARs over the event window \\
\hline $\mathrm{ACAR}$ & $\sum_{t=-1}^{1}\left|A R_{t}\right|$ \\
\hline Cartesian product of ARs in the event window: $\left|\prod_{t=-1}^{1}\left[1+A R_{t}\right]-1\right|$ \\
$\begin{array}{l}\text { Change in the standard deviation of daily stock returns before and after the } \\
\text { firm's annual securities report filing dates }\end{array}$ \\
$\qquad \sqrt{\frac{1}{30} \sum_{t=0}^{30}\left(R_{t}-\bar{R}_{t}\right)^{2}}-\sqrt{\frac{1}{30} \sum_{t=-30}^{0}\left(R_{t}-\bar{R}_{t}\right)^{2}}$
\end{tabular}

ASPREAD Difference between the average daily spread during the event window and the average daily spread during the estimation window

$$
\begin{aligned}
& \text { Average daily } \text { spread }_{\text {Event window }} \\
& \qquad- \text { Average daily spread } \\
& \qquad \text { Estimation window }
\end{aligned}
$$

AVOL Difference between the mean daily trading volume during the event window and the mean daily trading volume during the estimation window divided by the standard deviation of the daily trading volume during the estimation window

Average daily volume Event window $_{\text {vily }}$
$\frac{- \text { Average daily volume }}{\text { Estimation window }}$
STDDEV daily volume Estimation window $_{\text {vition }}$

\begin{tabular}{ll}
\hline XBRL & Dummy variable that is equal to 1 in the post-XBRL period and 0 otherwise \\
\hline SIZE & Natural log of market capitalization \\
\hline MB & Market-to-book ratio \\
\hline LPRATIO & Earnings-to-price ratio \\
\hline LOSS & Long-term debt divided by total assets \\
\hline TECH & $\begin{array}{l}\text { Dummy variable that is equal to } 1 \text { if the fiscal year's net income is negative } \\
\text { and } 0 \text { otherwise }\end{array}$ \\
\hline GOV & $\begin{array}{l}\text { Dummy variable that is equal to } 1 \text { for firms that are classified under IT \& } \\
\text { Services and } 0 \text { otherwise }\end{array}$ \\
\hline RETVAR & Percentage of shares held by foreign shareholders \\
\hline NEGCAR & Standard deviation of the firm's ARs during the estimation window \\
\hline CAAR & $\begin{array}{l}\text { Dummy variable that is } 1 \text { if cumulative ARs during the estimation window } \\
\text { are negative and } 0 \text { otherwise }\end{array}$ \\
\hline
\end{tabular}

